\title{
Investigación translacional en Oncología Radioterápica: una necesidad para el progreso científico
}

Muchos han sido los avances producidos en el ejercicio de la Oncología Radioterápica desde que el primer paciente fuera tratado hace ahora mas de un siglo. La experiencia clínica acumulada en las primeras décadas permitió establecer las dosis y fraccionamientos mas eficaces que, aún hoy día siguen vigentes. El uso de técnicas mas precisas de tratamiento, y el desarrollo de los aceleradores lineales, así como un mejor conocimiento de las dosis de tolerancia, aumentó el beneficio terapéutico, al disminuir las complicaciones de los tejidos sanos.

Debido a su ámbito de actuación local, parte de la contribución de la radioterapia al ámbito de la oncología son el conocimiento preciso del patrón de crecimiento de los tumores, la importancia de los hallazgos patológicos y los conceptos de enfermedad subclínica y control local.

El progreso de la Oncología Radioterápica se ha centrado en tres campos fundamentalmente: la asociación con quimioterápicos; mejoras técnicas, principalmente la planificación tridimensional; y la incorporación de los conocimientos de biología molecular a la clínica.

El desarrollo de esquemas de radioquimioterapia, apoyados por numerosos estudios aleatorizados, han establecido el estándar de tratamiento en diversas neoplasias, como cáncer de cérvix, recto y cabeza y cuello, entre otros.

El perfeccionamiento técnico a nivel de unidades de tratamiento, simuladores y sistemas de planificación ha permitido la realización de tratamientos con planificación tridimensional hasta mas novedosos como la intensidad modulada. La incorporación de estas técnicas, que permiten disminuir la dosis a los tejidos sanos, ha propiciado la administración de dosis mas altas.

En las últimas décadas, los avances producidos en biología molecular han tenido un impacto creciente en la Oncología Radioterápica. El conocimiento de la biología celular y molecular es el motor que mueve el avance de los tratamientos con radioterapia. Los campos en los cuales estos conocimientos tienen o tendrá una mayor repercusión son la radiobiología; el conocimiento de los determinantes moleculares de respuesta a la irradiación, tanto del tumor como de los tejidos sanos; y la posibilidad de un tratamiento con terapia génica o dirigido a modificar las rutas de traducción de señal desencadenadas por la irradiación.

Actualmente se han modificado algunos de los conceptos que se tenían acerca de la respuesta celular a la irradiación, gracias sobre todo al conocimiento de los mecanismos moleculares desencadenados por la misma ${ }^{1}$. El modelo radiobiológico actual contempla una serie de sensores del daño (peroxidación lipídica de la membrana, con la generación de reactive oxidative species (ROS), activación de receptores de membrana, el gen mutado de la ataxia-telangiectasia (ATM), o el nuclear factor kappa beta, entre otros), que va seguida de la activación de vías de traducción de señal intracitoplásmicas (RAS, ceramida, PKC, etc) que llevan la señal al núcleo activando genes precoces, como p53 o el complejo c-jun/c-fos, que intervienen en proliferación, reparación del DNA, apoptosis y cambios en el ciclo celular. Por otro lado, los productos de estos genes actúan como factores de transcripción de genes tardíos que codifican para factores de crecimiento y citoquinas, responsables de algunos de los efectos mas conocidos de la radioterapia. Entre ellos, el transforming growth factor (TGFb) implicado en la fibrosis radioinducida, ha sido el mas estudiado.

El estudio de los factores moleculares predictores de respuesta a la radioterapia es de suma importancia ya que permitirá en un futuro la elaboración de perfiles moleculares tumorales que nos ayuden a elegir el tratamiento mas adecuado. Por otro lado, estos estudios abren la posibilidad de modificar farmacológicamente aquellas alteraciones que producen radioresistencia (terapias dirigidas). Actualmente se encuentran en desarro- 
llo clínico determinados fármacos como los inhibidores del EGFR, antiangiogénicos, inhibidores de la COX2, e inhibidores de la farnesyl transferasa, entre otros. Aunque aún lejos de la clínica, la posibilidad de una terapia génica radiosensibilizante, consistente en la utilización de métodos moleculares para reemplazar genes defectivos o ausentes, o contrarrestar sobreexpresión de genes, está empezando a ser investigada.

Es imprescindible que todos estos estudios se enmarquen dentro de lo que ha venido denominándose investigación translacional referida a una cadena de sistemas experimentales mas o menos jerárquicos que convergerían en la clínica. Simplificando, los eslabones de esta cadena serían los estudios in vitro, modelos animales, estudios clínicos fase I-II, estudios fase III y estándar clínico. La integración de la investigación dentro de este esquema permite no solo dirigir mejor la experimentación preclínica, sino que abre la posibilidad de incorporar ideas desde la clínica hacia eslabones mas básicos².

En este número de la revista se presenta un trabajo de investigación de alto nivel, que ejemplifica lo expuesto mas arriba. La ataxia-telangiectasia es una enfermedad hereditaria autosómica recesiva que, aparte de sus otras alteraciones, presenta interés oncológico por la suceptibilidad al cáncer y la extrema radiosensibilidad que presentan estos pacientes. El gen mutado de la ataxia-telangiectasia (ATM) fue clonado en los $90^{3}$ y pertenece a la familia de las PI3 quinasas, que se activan tras el daño al DNA, ejerciendo el control sobre la p53. El grupo de Sánchez-Prieto y colaboradores, nos presentan parte de una amplia línea de investigación sobre el papel del ATM en la inducción de radiosensibilidad ${ }^{4}$. El trabajo aporta dos conclusiones muy importantes: por un lado, demuestra el control que ATM ejerce sobre la PKB/Akt, proteína clave en las rutas de supervivencia celular; y, por otro, establece que la radiosensibilidad de los pacientes de ataxia-telangiectasia está mediada por $\mathrm{PKB} /$ Akt. Estas observaciones abren un amplio potencial terapéutico al describir dianas específicas que, al ser manipuladas, incrementen la respuesta a la irradiación.

Sería deseable que la cadena de investigación no se rompiera y esta y otras líneas de trabajo puedan en el futuro tener una aplicación clínica para beneficio de nuestros pacientes oncológicos que, no debe olvidarse, es el fin último que nos mueve.

\section{Jesús Romero \\ Redactor Jefe Revista Oncología Servicio de Oncología Radioterápica Hospital Universitario Puerta de Hierro \\ Madrid}

\section{Bibliografía}

1. Dent P, Yacoub A, Contessa J, et al. Stress and Radiation-Induced Activation of Multiple Intracellular Signaling Pathways. Radiat Res 2003; 159:283-300.

2. The translational research chain: is it delivering the goods? Baumann M, Bentzen SM, Doerr W, et al. Int J Radiation Oncology Biol Phys, 2001; 49:345-351.

3. Savitsky K, Bar-Shira A, Gilad S, Rotman G, Ziv Y, Vanagaite, et al. A single ataxia telangiectasia gene with a product similar to PI-3 kinase. Science 1995; 268:1749-1753.

4. Guinea J, Martínez N, Aceves CI, et al. PKB/Akt media la radio sensibilidad asociada a Ataxia Telangiectasia. Oncología 2005; 28(7):329-337. 